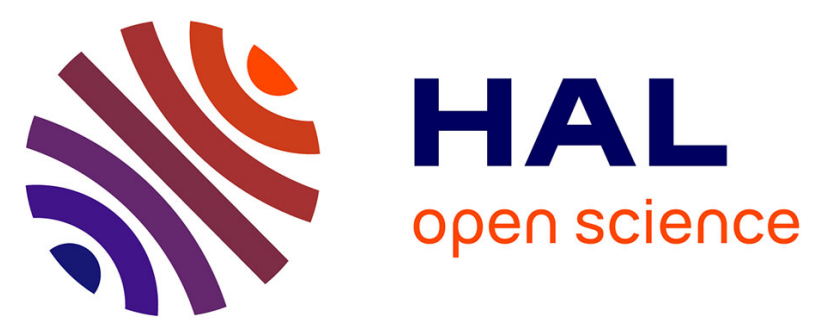

\title{
Impact of initial lipid content and oxygen supply on alcoholic fermentation in Champagne-like musts
}

Jean-Marie Sablayrolles, Thomas Ochando, Jean-Roch Mouret, Vincent Farines, Anne Humbert-Goffart

\section{To cite this version:}

Jean-Marie Sablayrolles, Thomas Ochando, Jean-Roch Mouret, Vincent Farines, Anne HumbertGoffart. Impact of initial lipid content and oxygen supply on alcoholic fermentation in Champagne-like musts. Macrowine 2016, Jun 2016, Changins, Switzerland. hal-01603363

\section{HAL Id: hal-01603363 https://hal.science/hal-01603363}

Submitted on 3 Jun 2020

HAL is a multi-disciplinary open access archive for the deposit and dissemination of scientific research documents, whether they are published or not. The documents may come from teaching and research institutions in France or abroad, or from public or private research centers.
L'archive ouverte pluridisciplinaire HAL, est destinée au dépôt et à la diffusion de documents scientifiques de niveau recherche, publiés ou non, émanant des établissements d'enseignement et de recherche français ou étrangers, des laboratoires publics ou privés.

\section{다(1)(2)}

Distributed under a Creative Commons Attribution - ShareAlike| 4.0 International 
1 Impact of initial lipid content and oxygen supply on alcoholic fermentation in

2 Champagne-like musts

3 Thomas Ochando ${ }^{1,2}$, Jean-Roch Mouret ${ }^{1}$, Anne Humbert-Goffard ${ }^{2}$, Jean-Marie

4 Sablayrolles $^{1}$, Vincent Farines ${ }^{1}$

5

$6 \quad{ }^{1}$ UMR SPO : INRA, Universite Montpellier, Montpellier SupAgro, 34060, Montpellier,

7 France

$8 \quad{ }^{2}$ Moët \& Chandon, F-51200 Epernay, France

9

10 *Corresponding author: Tel: +33-4-99-61-22-74; Fax:+33-4-99-61-28-51

11 E-mail address: vincent.farines@univ-montp1.fr

12 


\section{Abstract}

14 Available nitrogen, lipids, or oxygen are nutrients with major impact on the kinetics of winemaking fermentation. Assimilable nitrogen is usually the growth-limiting nutrient which availability determines the fermentation rate and therefore the fermentation duration. In some particular cases, as in Champagne, grape musts have high available nitrogen content and low turbidity, i.e., below 50 Nephelometric Turbidity Unit (NTU). In the case of low turbidity, the availability of lipids, particularly phytosterols, becomes limiting. In this situation, control of oxygenation, which is necessary for lipid synthesis by yeast, is

21 particularly crucial during fermentation.

22 To mimic and understand these situations, a synthetic medium simulating the average

23 composition of a Champagne must was used. This medium contained phytosterol (mainly

$24 \beta$-sitosterol) concentrations ranging from 0 to $8 \mathrm{mg} / \mathrm{L}$ corresponding to turbidity between 10

$25-90$ NTU. Population reached during the stationary phase and the maximum fermentation rate are conditioned by the initial phytosterol concentration determining the amount of nitrogen consumption. An early loss of viability was observed when the lipid concentrations were very low. For example, the viability continuously decreased during the stationary phase to a final value of $50 \%$ for an initial phytosterol concentration of $1 \mathrm{mg} / \mathrm{L}$. In some fermentations, $10 \mathrm{mg} / \mathrm{L}$ oxygen were added at the end of the growth phase to combine the effects of initial content of phytosterols in the musts and the de novo synthesis of ergosterol and unsaturated fatty acids induced by oxygen addition. Effect of oxygen supply on the fermentation kinetics was particularly significant for media with low phytosterol contents. For example, the maximum fermentation rate was increased by 1.4 -fold and the fermentation time was 70 hours shorter with oxygen addition in the medium containing 2 $\mathrm{mg} / \mathrm{L}$ of phytosterols. As a consequence of the oxygen supply, for the media containing 3 ,

375 and $8 \mathrm{mg} / \mathrm{L}$ of phytosterols, the assimilable nitrogen was completely exhausted and the 
38 fermentation kinetics, as well as the final populations and viabilities (greater than $90 \%$ ),

39 were identical for the 3 conditions. The impacts of the lipid content and additional oxygen

40 on acetate, glycerol and succinate synthesis were also studied. The phytosterols

41 decreased the acetate and increased the succinate synthesis, and oxygenation resulted in

42 a decrease in succinate formation.

43 This work highlights the similarities and differences between the effects of lipids and

44 oxygen on fermentation kinetics and yeast metabolism. This research highlights the need

45 for an optimal combined management of lipid content in the must via turbidity and

46 oxygenation, particularly in nitrogen-rich musts.

47 Keywords:

48 | Winemaking fermentation; Lipids; Nitrogen; Oxygen supply; Viability; Acetic acid. 49 


\section{Introduction}

51 Yeast Available Nitrogen (YAN) is an essential nutritional factor during alcoholic

52 fermentation. Assimilable nitrogen is used by yeasts for protein synthesis and cell growth.

53 Under winemaking conditions, nitrogen is usually the limiting nutrient, and it is highly

54 correlated with fermentation kinetics, especially the maximum $\mathrm{CO}_{2}$ production rate and the

55 final yeast population (M. Bely, Sablayrolles, and Barre 1990).

56 Therefore, observing slow fermentation under oenological conditions for Champagne is

57 paradoxical because Champagne musts, from chardonnay and pinot noir/pinot meunier

58 grape varieties, usually contain large concentrations of nitrogen compounds. For example,

59 between 1982 and 1989, the YAN levels in Champagne musts were between 200 and 420

$60 \mathrm{mg} \mathrm{N} / \mathrm{L}$ (Ribéreau-Gayon et al. 2012). This last observation suggests that nitrogen is

61 probably not the limiting factor in Champagne musts and that another nutrient is

62 responsible for the long fermentation durations obtained here.

63 During the white winemaking process, variable amounts of grape solids (which are

64 composed of heterogeneous particle deposits) can be found depending on the pressing

65 process and the clarification level. Grape solids are an important source of nutrients for

66 yeasts (Casalta et al. 2013; Casalta et al. 2016). They have been shown to contain

67 phytosterols ( $\beta$-sitosterol, campesterol, and stigmasterol) and fatty acids (palmitic acid,

68 oleic acid, linoleic acid, and $\alpha$-linoleic acid), which are localized in the coating of grape

69 berries and are assimilated by yeasts (Miele, Bouard, and Bertrand 1993). $\beta$-sitosterol

70 represents more than $70 \%$ of total phytosterols (Le Fur et al. 2015). The absorption of

71 phytosterols allows yeasts to compensate, at least partially, for a lack of oxygen

72 (Andreasen and Stier 1953) and a deficiency in long-chain fatty acids during fermentation

73 (Lorenz et al. 1986; Rodriguez et al. 1985). The assimilation of these phytosterols leads to

74 the increased viability of yeasts at the end of fermentation (Luparia et al. 2004). The 
75 Champagne winemaking practice consists in clarifying the must with a pectolytic enzyme to reach a turbidity level that is usually lower than 50 NTU at the end of the clarification

77 step. The excessive clarification of the must consists in an important removal of solid

78 particles (coming from grape skins) that are the primary sources of lipids and, more

79 precisely, of phytosterols. This removal results in lower yeast proliferation and a significant

80 decrease in the fermentation rate (Houtman and Du Plessis 1986).

The aim objective of this work is to better understand the oenological situation of

83 Champagne, that is characterized by high YAN contents and low phytosterol concentration

84 in the musts. Our final aim is to improve the management of fermentation by increasing the

85 fermentation rate and limiting the risks of sluggish fermentation caused by cell mortality by 86 adding phytosterols and/or oxygen during fermentation.

\section{Materials and methods}

\section{Strain}

The yeast strain used is a Saccharomyces cerevisiae strain isolated from Champenois

90 Champagne vineyard. It is a non-commercial dry active strain used by Moët \& Chandon.

91 Fermentation flasks were inoculated with $10 \mathrm{~g} / \mathrm{hl}$ active dry yeast previously rehydrated for

$9230 \mathrm{~min}$ at $30^{\circ} \mathrm{C}$ in a $50 \mathrm{~g} / \mathrm{l} \mathrm{glucose}$ solution $(1 \mathrm{~g}$ of dry yeast diluted in $10 \mathrm{ml}$ of this

93 solution).

\section{Fermentation media}

95 Fermentations were performed on a synthetic medium (SM) mimicking Champagne must

96 and derived from standard grape juice as described by Bely (Bely et al. 1990). This culture

97 medium contained $180 \mathrm{~g} / \mathrm{L}$ of sugars (90 g/L glucose and $90 \mathrm{~g} / \mathrm{L}$ fructose), $7 \mathrm{~g} / \mathrm{L}$ malic acid,

$987 \mathrm{~g} / \mathrm{L}$ tartric acid, salts $\left(0.75 \mathrm{~g} / \mathrm{L} \mathrm{KH}_{2} \mathrm{PO}_{4}, 0.50 \mathrm{~g} / \mathrm{L} \mathrm{K}_{2} \mathrm{SO}_{4}, 0.25 \mathrm{~g} / \mathrm{L} \mathrm{MgSO}{ }_{4}, 0.155 \mathrm{~g} / \mathrm{L} \mathrm{CaCl}\right.$, 
and $0.20 \mathrm{~g} / \mathrm{L} \mathrm{NaCl}$ ), vitamins (20 mg/L myo-inositol, $1.5 \mathrm{mg} / \mathrm{L}$ pantothenic acid, $0.25 \mathrm{mg} / \mathrm{L}$

\section{0}

101

102

103

\section{4}

105

106

107 thiamine, $2 \mathrm{mg} / \mathrm{L}$ nicotinic acid, $0.25 \mathrm{mg} / \mathrm{L}$ pyridoxine, and $0.003 \mathrm{mg} / \mathrm{L}$ biotin), and trace elements (4 mg/L MnSO 4,4 mg/L ZnSO 4,1 mg/L CuSO 4,1 mg/L KI, 0.4 mg/L CoCl 2,1 $\mathrm{mg} / \mathrm{L} \mathrm{H}_{3} \mathrm{BO}_{3}$, and $\left.1 \mathrm{mg} / \mathrm{L}\left(\mathrm{NH}_{4}\right)_{6} \mathrm{Mo}_{7} \mathrm{O}_{24}\right)$. The $\mathrm{pH}$ of the medium was adjusted to 3.1 with 10 $\mathrm{M} \mathrm{NaOH}$.

The source of nitrogen was a mixture of ammonium (30\%) and amino acids (70\%) as commonly found in pinot noir must. The assimilable nitrogen concentration was $360 \mathrm{mg}$ $\mathrm{N} / \mathrm{L}$. The composition of the amino acid solution was as follows (in $\mathrm{mg} / \mathrm{L}$ ): tyrosine (8.3), tryptophan (6.5), isoleucine (15.9), aspartate (15.1), glutamate (56.9), arginine (550.3), leucine (20.5), threonine (124.3), glycine (3.5), glutamine (180), alanine (221.3), valine (30.9), methionine (5.9), phenylalanine (20.8), serine (74.7), histidine (12.6), lysine (4.6),

cysteine (15.1) and proline (100.5). This solution was established after an assay of natural Champagne grape musts from pinot noir. To obtain $360 \mathrm{mg} / \mathrm{L}$ of assimilable nitrogen in the $\mathrm{SM}, 14.6 \mathrm{~mL}$ of a amino acid stock solution and $413 \mathrm{mg}$ of $\mathrm{NH}_{4} \mathrm{Cl}$ were added to 1 litre of medium.

The SM medium was initially supplemented with different concentrations of phytosterols (CAS: 85.451, Sigma Aldrich, Saint Quentin Fallavier, France). The stock solution was composed of $15 \mathrm{~g} / \mathrm{L}$ of $\beta$-sitosterol in Tween 80 and absolute ethanol (1:1, v/v). To obtain 2 $\mathrm{mg} / \mathrm{L}$ of initial phytosterols, $1 \mathrm{~mL} / \mathrm{L}$ of 10 times-diluted stock solution was added to the medium. Total desorption of oxygen was monitored by using a PreSens ${ }^{\circledR}$ oxygen probe.

\section{Fermentation conditions}

The fermentations were performed in 1.2-L glass fermenters with $1.1 \mathrm{~L}$ of medium containing $360 \mathrm{mg} / \mathrm{L}$ of assimilable nitrogen and various levels of phytosterols $(0-8 \mathrm{mg} / \mathrm{L})$ at $20{ }^{\circ} \mathrm{C} . \mathrm{CO}_{2}$ released was measured from an accurate and automatic online monitoring of weight loss (Sablayrolles et al., 1987). 
125 During fermentation, the total cell population was determined using a Beckman Coulter counter (Model Z2, Beckman-Coulter, Margency, France) that was fitted with a $100 \mu \mathrm{m}-$ 127 aperture probe.

\section{Cell viability}

129 The cell viability was determined by flow cytometry using a BD Accuri ${ }^{\mathrm{TM}}$ C6 cytometer (BD 130 Biosciences, Le Pont de Claix, France). The samples were centrifuged (5 min at 14,000 x $131 \mathrm{~g})$. The supernatants were removed and the pellets were then diluted with Phosphate132 Buffered Saline $(1 \mathrm{X})$ to reach 5 to $10 \times 10^{6}$ cells $/ \mathrm{mL}$. For staining, propidium iodide $(\mathrm{PI})$ 133 was added to the cell suspension $(5 \mu \mathrm{L}$ of PI at $100 \mathrm{mg} / \mathrm{mL}$ in $500 \mathrm{~mL}$ of centrifuged and 134 diluted sample), mixed by gentle shaking and incubated for $10 \mathrm{~min}$ at room temperature in 135 the dark, then placed on ice before the fluorescence measurement by flow cytometry. 136 Propidium iodide is a fluorescent nucleic acid stain that cannot penetrate intact cell membranes. Propidium iodide fluorescence (with excitation using a 488-nm laser and 138 emission at $575 \mathrm{~nm}$ ) was collected via a 670-nm large-pass filter (Fluorescence 3).

139 Viability was determined as the percentage of intact and fragile cells among all the cells 140 (Delobel et al. 2012).

\section{Bubble-free oxygenation system}

142 Oxygen was added by using the bubble-free oxygenation system developed by Moenne et 143 al. 2013. To add $10 \mathrm{mg} / \mathrm{L}$ of oxygen over 120 minutes, the conditions were set up as

144 follows: length of the silicone tube: $0.4 \mathrm{~m}$, liquid flow rate: $120 \mathrm{~mL} / \mathrm{min}$, and maximum 145 Oxygen Transfer Rate (OTRm): $5 \mathrm{mg} / \mathrm{L} . \mathrm{h}$. The oxygen addition was performed at the 146 maximum rate of $\mathrm{CO}_{2}$ production corresponding to the end of the cellular growth phase 147 (Sablayrolles and Barre 1986). 
149 The ammonium concentration was determined enzymatically (RBiopharm AG ${ }^{\mathrm{TM}}$,

150 Darmstadt, Germany). The free amino acid content of the must was determined by cation

151 exchange chromatography, with post-column ninhydrin derivatization (Biochrom 30,

152 Biochrom ${ }^{\mathrm{TM}}$, Cambridge, UK) as described by (Crepin et al. 2012).

\section{Determination of metabolite concentrations}

154 The ethanol, glycerol, succinate and acetate concentrations were determined by HPLC

155 (HPLC 1290 Infinity, Agilent ${ }^{\mathrm{TM}}$ Technologies, Santa Clara, California, USA) on a

156 Phenomenex Rezex ROA column (Phenomenex ${ }^{\mathrm{TM}}$, Le Pecq, France) at $60^{\circ} \mathrm{C}$. The

157 column was eluted with $0.005 \mathrm{~N} \mathrm{H}_{2} \mathrm{SO}_{4}$ at a flow rate of $0.6 \mathrm{~mL} / \mathrm{min}$. The acetic acid

158 concentration was determined with a UV meter at $210 \mathrm{~nm}$; the concentrations of the other

159 compounds were determined with a refractive index detector. The analysis was performed

160 with an Agilent ${ }^{\mathrm{TM}}$ EZChrom software package.

\section{Results}

163 In the present work, we have evaluated the effects of the initial phytosterol concentration in

164 the must, with and without oxygen supplementation during fermentation, on the

165 fermentative kinetic profiles, population levels, nitrogen consumption and viability in the synthetic medium mimicking Champagne must conditions. We have used different levels levels of turbidity between 10 - 90 NTU.

170 In this section, we focused on the effect of the initial phytosterol concentration in the must,

171 from 0 to $8 \mathrm{mg} / \mathrm{L}$, simulating different levels of turbidity. 
173 As shown in figure 1, when the initial phytosterol concentration increased, the maximum

174 fermentation rate of $\mathrm{CO}_{2}$ production $\left(\mathrm{V}_{\max }\right)$ increased from 0.4 to $1.3 \mathrm{gCO}_{2} / \mathrm{L} . \mathrm{h}$, and the

175 fermentation duration was reduced from stuck fermentation to $150 \mathrm{~h}$. The increase in the

176 phytosterol content also resulted in higher final population levels. The population level

177 during the stationary phase was much lower during slow fermentation, with 20 million

178 cells $/ \mathrm{mL}$ corresponding to fermentation without phytosterols. By contrast, the maximum

179 amount of initial phytosterols (8 $\mathrm{mg} / \mathrm{L}$ ) led to a larger population, reaching 120 million

180 cells $/ \mathrm{mL}$. Consequently, the $\mathrm{V}_{\max }$ value can be correlated to the total cell number value

181 during the stationary phase with a regression coefficient of 0.989 (data not shown). The

182 initial phytosterol concentration also directly impacted the duration of the fermentation and

183 the cell number that was reached at the end of the growth phase. These data confirm the

184 key role of phytosterol content in our fermentation conditions.

\section{Cellular viability}

186 An early loss of viability was observed in musts containing very low lipid concentrations

(figure 2). When the phytosterol content is higher than $2 \mathrm{mg} / \mathrm{L}$, the viability value remained

higher than $80 \%$ during the major part of the fermentation process. For phytosterol

concentrations equal to 5 and $8 \mathrm{mg} / \mathrm{L}$, the kinetics of cellular viability were similar to that obtained at $3 \mathrm{mg} / \mathrm{L}$ (data not shown).

\section{Nitrogen consumption}

Assimilable nitrogen was monitored at $60 \%$ fermentation, i.e., during the stationary phase, when nitrogen consumption has ceased (Crepin et al. 2012), and before nitrogen release occurs as a result of mortality. The assimilable nitrogen was not exhausted, with the exception of the fermentation performed with $8 \mathrm{mg} / \mathrm{L}$ of phytosterols. These results confirm previous observations of natural musts (Casalta, Cervi, Salmon, \& Sablayrolles, 2013).

197 The number of cells during the stationary phase is correlated with nitrogen consumption 
$198\left(R^{2}=0.987\right)$, as shown in figure 3. Moreover, the initial nitrogen concentration is identical

199 under each condition. Thus, the initial concentration of phytosterols determined the

200 amount of nitrogen that was assimilated by the yeast.

201 Table 1 details the residual ammonium and major amino acid concentrations for different

202 initial levels of phytosterols. The sum of the arginine and alanine concentrations

203 represents $46 \%$ of the initial assimilable nitrogen, and they represent more than $60 \%$ of

204 the final residual assimilable nitrogen without phytosterols. When the amount of residual

205 nitrogen decreases, the proportion of residual arginine and alanine increases and reaches

206 over $90 \%$ at $5 \mathrm{mg} / \mathrm{L}$ phytosterol. This result confirms that these two amino acids are

207 consumed late, as previously observed by (Crepin et al. 2012). We also noted an increase

208 in residual proline with the increase in the initial phytosterol concentration (table 1). This

209 observation can be explained by the fact that even if proline cannot be assimilated under

210 anaerobic conditions (Brandriss and Magasanik 1979), it is produced from arginine

211 degradation (Martin et al. 2003).

Effects of oxygen supplementation on fermentation

213 By inducing the biosynthesis of ergosterol and unsaturated fatty acid by yeasts, the

214 addition of oxygen during fermentation is one of the levers that is used to improve

215 fermentation (Andreasen and Stier 1953; Rosenfeld et al. 2003; Sablayrolles and Barre

216 1986). The best timing for an oxygen supply during fermentation is towards the end of the

217 growth phase (Sablayrolles and Barre 1986), i.e., close to the maximum rate of $\mathrm{CO}_{2}$

218 production.

220 The oxygen supply had a positive impact on each condition (figure 4). This addition

221 increased the maximum rate of $\mathrm{CO}_{2}$ production and the cell number, resulting in a

222 reduction of the fermentation duration. The efficacy of oxygen addition was much higher

223 for musts that were highly deficient in phytosterols. Without any initial phytosterol, the 
224 addition of $10 \mathrm{mg} / \mathrm{L}$ of oxygen made the complete consumption of sugars possible, for a

225 high increase in the maximum rate of $\mathrm{CO}_{2}$ production $\left(0.3\right.$ to $\left.1.1 \mathrm{gCO}_{2} / \mathrm{L}\right)$ and the cell

226 number (20 to 90 million cells $/ \mathrm{mL}$ ). When the phytosterol content is $3 \mathrm{mg} / \mathrm{L}$, the increase in

227 these two parameters is lower: from 1.0 to $1.4 \mathrm{~g} \mathrm{CO}_{2} / \mathrm{L}$ for the maximum rate of $\mathrm{CO}_{2}$

228 production; and from 90 to 140 million cells $/ \mathrm{mL}$ for the cell number. Finally, above a

229 threshold phytosterol content ( $3 \mathrm{mg} / \mathrm{L})$, the fermentation kinetics and cell numbers during

230 the stationary phase were identical as a consequence of oxygen added at $10 \mathrm{mg} / \mathrm{L}$.

\section{Nitrogen consumption}

\section{2}

233

234

\section{Following the addition of $10 \mathrm{mg} / \mathrm{L}$ of oxygen, - the nitrogen consumption was} systematically increased (figure 5) by the addition of $10 \mathrm{mg} / \mathrm{L}$ of oxygen (figure 5). When oxygen was added, at a phytosterol concentration of $3 \mathrm{mg} / \mathrm{L}$ or above, the YAN was exhausted. These modalities can be classified into two groups, in which the first is composed of fermentations with residual nitrogen; and the second is without residual nitrogen and with the equivalent fermentation kinetics and numbers of cells. This result indicates that under Champagne oenological conditions (low turbidity and high assimilable nitrogen levels), the oxygen supply had two effects: lipid synthesis activation and increase of nitrogen consumption.

\section{Cellular viability}

The addition of $10 \mathrm{mg} / \mathrm{L}$ of oxygen to the culture medium that contained no phytosterol resulted in cell viability maintenance at its maximum value throughout the fermentation process (figure 2). This observation is also true for all the conditions involving phytosterols (dataset not shown).

\section{Effects of the phytosterol concentration and oxygen on metabolite production}

The analysis of some primary metabolites shows that the effects of phytosterols and oxygen have some similarities. Even if the final concentrations of acetic acid, succinic acid and glycerol are different, we can distinguish two global evolutions: (i) under $3 \mathrm{mg} / \mathrm{L}$, in 
249 which a strong evolution is observed; and (ii) above $3 \mathrm{mg} / \mathrm{L}$, in which the evolution is

250 limited, as shown in figure 6.

251 First, we noticed that the increase in the initial amount of phytosterols strongly reduced

252 acetate production, as observed in previous studies (Delfini and Costa 1993; Luparia et al.

253 2004). The production of this organic acid was divided by 1.8 between $0.5 \mathrm{mg} / \mathrm{L}$ and 3

$254 \mathrm{mg} / \mathrm{L}$ of phytosterols. A good correlation was established between the final acetate

255 concentration and the level of nitrogen assimilated by the yeast $\left(R^{2}=0.98\right)$. In addition we

256 did not find any effect of added oxygen on the final acetate concentration.

257 Second, we observed that the increase of initial phytosterols increased the final succinate

258 concentration. Between 1 and $8 \mathrm{mg} / \mathrm{L}$, the final succinate doubled. In addition, we also

259 found that the final succinate concentration was correlated with the amount of nitrogen that

260 was assimilated by the yeast $\left(R^{2}=0.979\right)$. However, with oxygen, the amount of succinate

261 is stable $(0.3 \mathrm{mg} / \mathrm{L})$ and independent of the initial phytosterol concentration.

262 Finally, from 0 to $3 \mathrm{mg} / \mathrm{L}$ phytosterols, a reduction of $1 \mathrm{~g} / \mathrm{L}$ in the final glycerol

263 concentration was obtained. Above $3 \mathrm{mg} / \mathrm{L}$, the final glycerol concentration was stable at

264 approximately $6 \mathrm{~g} / \mathrm{L}$. Moreover; the added oxygen did not have any effect on the final

265 glycerol concentration.

\section{Discussion}

267 Must turbidity, and oxygen are essential for white wine alcoholic fermentation, and

268 Champagne conditions provide an excellent example for distinguishing among the different 269 mechanisms that are involved. These conditions are usually characterized by high levels

270 of Yeast Available Nitrogen (YAN) in musts and low amounts of solid particles, which is the

271 result of dramatic clarification, with turbidity levels lower than 50 NTU. Grape solids

272 provide reserves of sterols and fatty acids for yeast during anaerobic fermentation (Le Fur

273 et al. 2015; Casalta et al. 2016; Ruggiero et al. 2013). Therefore, Champagne musts are 
274 characterized by lipid deficiencies, and assimilable nitrogen is usually the limiting nutrient

275 in wine-making fermentation, including in white winemaking.

276 In a synthetic medium that was used for simulating the average composition of

277 Champagne musts, we observed slow fermentation when the culture medium was

278 deprived of lipid resources and oxygen. Under this condition, the consumption of

279 assimilable nitrogen and the final population were very low (figures 1 and 5 and table 2).

280 The population was limited by the amount of sterols and fatty acids available to synthesize

281 the plasmic membrane; low turbidity induces low lipid availability, and under strict

282 anaerobic conditions, yeast is not able to synthesize ergosterol and unsaturated fatty acids

283 (Andreasen and Stier 1953; Andreasen and Stier 1954). Increasing the initial content of

284 lipids in the must (turbidity) led to higher nitrogen consumption during the alcoholic

285 fermentation process. Total nitrogen depletion was obtained for an initial phytosterol

286 content of $8 \mathrm{mg} / \mathrm{L}$. This value depends on the strain and on the initial nitrogen content

287 (Rollero et al. 2015). As a consequence of the higher nitrogen consumption, the cell

288 population and the maximum $\mathrm{CO}_{2}$ production rate were increased and the fermentation

289 duration was reduced. Adjusting the turbidity appears to be necessary for improving the

290 fermentation kinetic of white wine fermentations (Casalta et al. 2013). Using another

291 approach, providing an oxygen supply during fermentation favours the synthesis of

292 ergosterol by yeast (Andreasen and Stier 1953; Andreasen and Stier 1954) and allows for

293 the correction of lipid deficiency (figure 4 and 5 and table 1). We added $10 \mathrm{mg} / \mathrm{L}$ oxygen at

294 the end of the growth phase, which is considered the best timing for an oxygen supply

295 (Sablayrolles and Barre 1986; Blateyron and Sablayrolles 2001; Fornairon-Bonnefond et 296 al. 2003; Rosenfeld et al. 2003). Following the addition of oxygen, a switch from lipid-

297 limited to nitrogen-limited fermentation occurred for a $3 \mathrm{mg} / \mathrm{L}$ phytosterol content. Above

298 this lipid concentration, the total depletion of assimilable nitrogen resulted in a

299 "standardization" of the fermentation kinetics with similar values for the fermentation 
duration, maximum $\mathrm{CO}_{2}$ production rate and population. This effect is confirmed visible on figure 7, where principal component analysis (PCA) allows evaluating the significanceeffect of lipids (turbidity) and oxygen on the fermentation kinetics (duration. nitrogen consumption, total cell, viability) and organoleptic aspec the synthesis if some key

tmetabolites -(acetic acid, glycerol). It is thus necessary to combine the management of turbidity and oxygen to deplete the assimilable nitrogen, especially in the case of nitrogenrich musts.

Champagne conditions are also an excellent model for studying the impact of nitrogen-lipid balance management on the modulation of cell viability during the fermentation process. Ethanol is the primary cause of mortality because it affects the integrity of the cell membrane, damages the permeability of numerous ionic species, and decreases the fluidity of the plasma membrane, leading to the dissipation of the transmembrane electrochemical potential, and subsequently acidifies the intracellular and vacuolar conditions (Salgueiro, Sá-Correia, and Novais 1988; Teixeira et al. 2009). Increasing the initial phytosterol concentration and/or the addition of oxygen dramatically improved the cell viability (figure 2). This positive effect of phytosterols on viability has also been observed in natural musts (Casalta et al. 2013). The effects of phytosterols and oxygen on viability are comparable. However, the mechanisms are slightly different. Under anaerobic conditions, yeast is able to: (i) incorporate exogenous phytosterols and fatty acids as an external source of lipids that is directly provided by the medium (Daum et al. 1998; Vanegas et al. 2012; Luparia et al. 2004); and (ii) synthesize endogenous unsaturated fatty acids and sterols in the presence of oxygen, but, in that case, the major sterol is ergosterol. Molecular oxygen is required for squalene cyclization to sterols and the subsequent demethylation of lanosterol, and for unsaturated fatty acid biosynthesis (Parks 1978). Ergosterol induces the formation of a liquid-ordered phase (Sankaram and Thompson 1991; Marsh 2009) and plays an important role in modulating the membrane 
326 dynamic structure and mechanical properties (Bacia, Schwille, and Kurzchalia 2005; Hung

327 et al. 2007). Unsaturated fatty acids and sterols play an important role in protecting the

328 yeast plasma membrane against ethanol-induced interdigitation (Vanegas et al. 2012).

329 However, ergosterol is certainly more efficient than phytosterols at maintaining yeast

330 membrane integrity (Luparia et al. 2004).

331 Many other metabolic pathways are also influenced by the management of the phytosterol

332 content in musts and/or oxygen addition. We focused on the production of three of the

333 primary metabolites in central carbon metabolism: acetic acid, glycerol and succinic acid.

334 Acetic acid plays a crucial role in the organoleptic balance of wine; it is the primary

335 component of volatile acidity. This compound is produced by the oxidation of acetaldehyde

336 via the cytosolic pyruvate dehydrogenase $(\mathrm{PDH})$ bypass (Remize, Andrieu, and Dequin

337 2000). Under our experimental conditions, when lipids were the limiting nutrient, we

338 observed a negative correlation between the final acetic acid concentration and the initial

339 phytosterol content. Acetyl-CoA carboxylase is generally considered the rate-limiting step

340 in lipogenesis (Donaldson 1979). Thus, it can be hypothesized that supplementing the

341 culture medium with lipids decreases the cellular demand in lipids and thus the intensity of

342 the metabolic flux from acetyl-CoA to lipid synthesis. The decrease in this specific

343 metabolic flux results in the lower production of acetic acid, which is an intermediate of this

344 metabolic pathway (figure 6 and 7) (Moreno-Arribas and Polo 2009). In the case of the

345 oxygen supply, no effect on acetic acid production was noted (figure 6). This phenomenon

346 can be explained by the demand of lipid synthesis and the redox balance (NADPH/NADP)

347 turnover. The synthesis of ergosterol and unsaturated fatty acids requires both oxygen and

$348 \mathrm{NADPH}$, whereas only NADPH is necessary to synthesize diacylglycerol or saturated fatty

349 acids (Parks 1978). Therefore, in the presence of oxygen, the NADPH demand is still high

350 for lipid biosynthesis; thus, the turnover of NADPH to NADP is high. The conversion of

351 acetaldehyde to acetic acid allows for the renewal of the NAPD to NADPH (Remize, 
352 Andrieu, and Dequin 2000). When oxygen is added, most of the acetyl-CoA is used for

353 lipid synthesis, without modification of the acetic acid excretion. Oxygen allows for the

354 complete utilization of acetyl-CoA for lipid synthesis whereas turbidity (phytosterol + fatty

355 acids) provides key components directly, which does not require acetyl-CoA.

356 Glycerol, which may contribute positively to the quality of wine, is produced by yeasts to

357 maintain the redox stability (NADH/NAD turnover) and as a response to cellular stress

358 (Vriesekoop, Haass, and Pamment 2009; Nevoigt 1997), in particular osmotic stress

359 (Hohmann 1997). Glycerol formation results from the L-Glycerol 3-phosphate

360 dephosphorylation. L-Glycerol 3-phosphate is also the first step of triglyceride

361 biosynthesis,(Zheng 2001). In our conditions where lipids are the limiting nutrient, glycerol is negatively correlated to the phytosterol content (figure 6). Whereas, in 'standard' oenological situations, i. e. when nitrogen is the limiting nutrient, glycerol production increases with the lipid content (Luparia et al. 2004). This difference can be explained by the modulation of the activation of triglyceride pathway. In the case of strong lipid deficiency, biosynthesis of triglyceride is strongly activated. Yeast produces L-Glycerol 3phosphate and the excessive flow is converted in to glycerol. When the initial lipid content increases, the amount of fatty acids increases and triglyceride biosynthesis is triggered. Thus, the accumulation of glycerol in the media is lower, figure 7 . When oxygen is added to the media, we do not observe a difference in glycerol production (such as acetic acid production) because turbidity (phytosterol + fatty acids) provides key components which facilitated triglyceride production.

Succinic acid is the predominant non-volatile organic acid formed during fermentation, and

375 it is a good metabolic marker of the Krebs cycle. In our study, succinic acid production was increased by phytosterols and therefore dependent on the amount of nitrogen consumed and biomass produced, as already observed in previous studies (Muratsubaki 1987; 
378 Verduyn et al. 1990; Albers et al. 1996). The biosynthesis of most amino acids involves

379 transamination reactions in which glutamate serves as an amino group donor to form $\alpha$ -

380 ketoglutarate, which can be converted into succinic acid via two metabolic pathways: the

381 GABA bypass, or via $\alpha$-ketoglutarate dehydrogenase and succinyl-CoA synthetase

382 (Camarasa, Grivet, and Dequin 2003). Consequently, when nitrogen consumption is

383 higher, the glutamate demand for transamination increases, resulting in a higher

384 accumulation of $\alpha$-ketoglutarate and a more important synthesis of succinic acid. Thus,

385 succinic acid evolution is an indirect consequence of the effect of phytosterols on nitrogen

386 consumption under lipid-limiting conditions. The effect of oxygen is slightly different. Under

387 oxygenated conditions, succinate synthesis remained almost stable and independent of

388 the nitrogen consumption quantity. A possible explanation is a lower flux from acetyl-CoA

389 to $\alpha$-ketoglutarate because of the greater mobilization of acetyl-CoA for lipid production,

390 regardless of the initial phytosterol content.

\section{Conclusion}

392 This work highlights the similarities but also the differences in the effects of lipids and

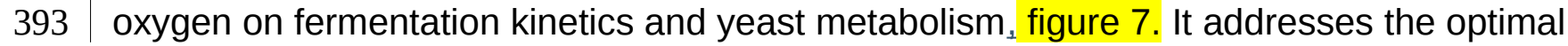

394 combined management of turbidity and oxygenation, in particular in nitrogen-rich musts.

395 The best strategy is a combination of: (i) a moderate amount of solids in the must,

396 corresponding to $2-3 \mathrm{mg} / \mathrm{L}$ phytosterols, to permit enough nitrogen consumption and yeast

397 growth without having a negative effect on the wine quality, especially acetic acid

398 formation; and (ii) an addition of approximately $10 \mathrm{mg} / \mathrm{L}$ oxygen at the end of the growth

399 phase as suggested by Blateyron and Sablayrolles (2001), to maintain the viability of the

400 yeasts. The application of this strategy may not be easily applicable at an industrial scale.

401 There is a need for the complete control of the quantity of oxygen transfer, which is difficult

402 in large tanks. Another difficulty is to quantify precisely the relationship between 
403 phytosterols and turbidity. Even if it is well-known that turbidity is related to the amount of 404 phytosterols that are available in the must, this relationship depends on the pressing and 405 clarification process and also on the grape varieties (Casalta et al., 2016).

406 In the future, the two major challenges will be: (i) the combined optimization of oxygen,

407 solid grape particles and nitrogen in the case of nitrogen-poor musts; and (ii) the control of 408 the wine aroma profile (Rollero et al. 2015).

409 


\section{Bibliography}

Albers, Eva, Christer Larsson, Gunnar Lidén, Claes Niklasson, and Lena Gustafsson 1996 Influence of the Nitrogen Source on Saccharomyces Cerevisiae Anaerobic Growth and Product Formation. Applied and Environmental Microbiology 62(9): 3187-3195.

Andreasen, A. A., and T. J. Stier

1954 Anaerobic Nutrition of Saccharomyces Cerevisiae. II. Unsaturated Fatty Acid Requirement for Growth in a Defined Medium. Journal of Cellular Physiology 43(3): 271-281.

Andreasen, A. A., and T. J. B. Stier

1953 Anaerobic Nutrition of Saccharomyces Cerevisiae. I. Ergosterol Requirement for Growth in a Defined Medium. Journal of Cellular Physiology 41(1): 23-36.

Bacia, Kirsten, Petra Schwille, and Teymuras Kurzchalia

2005 Sterol Structure Determines the Separation of Phases and the Curvature of the LiquidOrdered Phase in Model Membranes. Proceedings of the National Academy of Sciences of the United States of America 102(9): 3272-3277.

Bely, M., J. M. Sablayrolles, and P. Barre

1990 Description of Alcoholic Fermentation Kinetics: Its Variability and Significance. American Journal of Enology and Viticulture 41(4): 319-324.

Blateyron, L., and J. M. Sablayrolles

2001 Stuck and Slow Fermentations in Enology: Statistical Study of Causes and Effectiveness of Combined Additions of Oxygen and Diammonium Phosphate. Journal of Bioscience and Bioengineering 91(2): 184-189.

\section{Brandriss, M. C., and B. Magasanik}

1979 Genetics and Physiology of Proline Utilization in Saccharomyces Cerevisiae: Enzyme Induction by Proline. Journal of Bacteriology 140(2): 498-503.

Camarasa, Carole, Jean-Philippe Grivet, and Sylvie Dequin

2003 Investigation by 13C-NMR and Tricarboxylic Acid (TCA) Deletion Mutant Analysis of Pathways for Succinate Formation in Saccharomyces Cerevisiae during Anaerobic Fermentation. Microbiology (Reading, England) 149(Pt 9): 2669-2678.

Casalta, E., M.F. Cervi, J.M. Salmon, and J.M. Sablayrolles

2013 White Wine Fermentation: Interaction of Assimilable Nitrogen and Grape Solids: Interaction of Assimilable Nitrogen and Grape Solids on Alcoholic Fermentation under Oenological Conditions. Australian Journal of Grape and Wine Research 19(1): 47-52.

Casalta, E., A. Vernhet, J.-M. Sablayrolles, C. Tesniere, and J.-M. Salmon 2016 Review: Characterization and Role of Grape Solids during Alcoholic Fermentation under Enological Conditions. American Journal of Enology and Viticulture 67(2): 133-138.

Crepin, L., T. Nidelet, I. Sanchez, S. Dequin, and C. Camarasa 2012 Sequential Use of Nitrogen Compounds by Saccharomyces Cerevisiae during Wine 
Fermentation: A Model Based on Kinetic and Regulation Characteristics of Nitrogen Permeases. Applied and Environmental Microbiology 78(22): 8102-8111.

Daum, Gunther, Norman D. Lees, Martin Bard, and Robert Dickson

1998 Biochemistry, Cell Biology and Molecular Biology of Lipids ofSaccharomyces Cerevisiae. Yeast 14(16): 1471-1510.

Delfini, C., and A. Costa

1993 Effects of the Grape Must Lees and Insoluble Materials on the Alcoholic Fermentation Rate and the Production of Acetic Acid, Pyruvic Acid, and Acetaldehyde. American Journal of Enology and Viticulture 44(1): 86-92.

Delobel, P., M. Pradal, B. Blondin, and C. Tesniere

2012 A “fragile Cell” Sub-Population Revealed during Cytometric Assessment of Saccharomyces Cerevisiae Viability in Lipid-Limited Alcoholic Fermentation: Yeast Viability in Lipid-Limited Media. Letters in Applied Microbiology 55(5): 338-344.

Donaldson, W. E.

1979 Regulation of Fatty Acid Synthesis. Federation Proceedings 38(12): 2617-2621.

Fornairon-Bonnefond, Caroline, Evelyne Aguera, Christelle Deytieux, Jean-Marie Sablayrolles, and Jean-Michel Salmon

2003 Impact of Oxygen Addition during Enological Fermentation on Sterol Contents in Yeast Lees and Their Reactivity towards Oxygen. Journal of Bioscience and Bioengineering 95(5): 496503.

Hohmann

1997 Shaping up: The Response of Yeast to Osmotic Stress.: 101-145.

Houtman, A. C., and C. S. Du Plessis

1986 Nutritional Deficiencies of Clarified White Grape Juices and Their Correction in Relation to Fermentation. S. Afr. J. Enol. Vitic 7(1): 39.

Hung, Wei-Chin, Ming-Tao Lee, Fang-Yu Chen, and Huey W. Huang

2007 The Condensing Effect of Cholesterol in Lipid Bilayers. Biophysical Journal 92(11): 39603967.

Le Fur, Y., Chantal Hory, Marie-Hélène Bard, and Aline Olsson

2015 Evolution of Phytosterols in Chardonnay Grape Berry Skins during Last Stages of Ripening. VITIS-Journal of Grapevine Research 33(3): 127.

Lorenz, R. Todd, R. J. Rodriguez, T. A. Lewis, and L. W. Parks

1986 Characteristics of Sterol Uptake in Saccharomyces Cerevisiae. Journal of Bacteriology 167(3): 981-985.

Luparia, V., V. Soubeyrand, T. Berges, A. Julien, and J.-M. Salmon 2004 Assimilation of Grape Phytosterols by Saccharomyces Cerevisiae and Their Impact on Enological Fermentations. Applied Microbiology and Biotechnology 65(1). http://link.springer.com/10.1007/s00253-003-1549-3, accessed March 17, 2015.

Marsh, Derek 
2009 Cholesterol-Induced Fluid Membrane Domains: A Compendium of Lipid-Raft Ternary Phase Diagrams. Biochimica et Biophysica Acta (BBA) - Biomembranes 1788(10): 2114-2123.

Martin, O., M. C. Brandriss, G. Schneider, and A. T. Bakalinsky

2003 Improved Anaerobic Use of Arginine by Saccharomyces Cerevisiae. Applied and

Environmental Microbiology 69(3): 1623-1628.

Miele, Alberto, Jacques Bouard, and Alain Bertrand

1993 Fatty Acids From Lipid Fractions of Leaves and Different Tissues of Cabernet Sauvignon Grapes. American Journal of Enology and Viticulture 44(2): 180-186.

Moenne, María Isabel, Jean-Roch Mouret, Jean-Marie Sablayrolles, Eduardo Agosin, and Vincent Farines

2013 Control of Bubble-Free Oxygenation with Silicone Tubing during Alcoholic Fermentation. Process Biochemistry 48(10): 1453-1461.

Moreno-Arribas, M. Victoria, and Carmen Polo, eds.

2009 Wine Chemistry and Biochemistry. New York, NY: Springer.

Muratsubaki, $\mathrm{H}$.

1987 Regulation of Reductive Production of Succinate under Anaerobic Conditions in Baker's Yeast. Journal of Biochemistry 102(4): 705-714.

Nevoigt, E

1997 Osmoregulation and Glycerol Metabolism in the Yeast Saccharomyces Cerevisiae. FEMS Microbiology Reviews 21(3): 231-241.

Parks, L. W.

1978 Metabolism of Sterols in Yeast. CRC Critical Reviews in Microbiology 6(4): 301-341.

Remize, F., E. Andrieu, and S. Dequin

2000 Engineering of the Pyruvate Dehydrogenase Bypass in Saccharomyces Cerevisiae: Role of the Cytosolic Mg2+ and Mitochondrial K+ Acetaldehyde Dehydrogenases Ald6p and Ald4p in Acetate Formation during Alcoholic Fermentation. Applied and Environmental Microbiology 66(8): 3151-3159.

Ribéreau-Gayon, Pascal, Denis Dubourdieu, Bernard Donèche, and Aline Lonvaud 2012 Traité d’oenologie, Tome 1 - 6e éd - Microbiologie du vin. Vinifications. Pratiques Vitivinicoles. Faculté d’oenologie de Bordeaux: Dunod;

Rodriguez, Russell J., Christopher Low, Cynthia D.K. Bottema, and Leo W. Parks 1985 Multiple Functions for Sterols in Saccharomyces Cerevisiae. Biochimica et Biophysica Acta (BBA) - Lipids and Lipid Metabolism 837(3): 336-343.

Rollero, Stéphanie, Audrey Bloem, Carole Camarasa, et al.

2015 Combined Effects of Nutrients and Temperature on the Production of Fermentative Aromas by Saccharomyces Cerevisiae during Wine Fermentation. Applied Microbiology and Biotechnology 99(5): 2291-2304.

Rosenfeld, E., B. Beauvoit, B. Blondin, and J.-M. Salmon

2003 Oxygen Consumption by Anaerobic Saccharomyces Cerevisiae under Enological 
Conditions: Effect on Fermentation Kinetics. Applied and Environmental Microbiology 69(1): 113561121.

Ruggiero, Antonietta, Sara Vitalini, Nedda Burlini, Silvana Bernasconi, and Marcello Iriti 2013 Phytosterols in Grapes and Wine, and Effects of Agrochemicals on Their Levels. Food Chemistry 141(4): 3473-3479.

Sablayrolles, J. M., and P. Barre

1986 Evaluation Des Besoins En Oxygène de Fermentations Alcooliques En Conditions

Oenologiques Simulées. Sciences Des Aliments 6(n³): 373-383.

Salgueiro, Sancha P., Isabel Sá-Correia, and Júlio M. Novais

1988 Ethanol-Induced Leakage in Saccharomyces Cerevisiae: Kinetics and Relationship to Yeast Ethanol Tolerance and Alcohol Fermentation Productivity. Applied and Environmental

Microbiology 54(4): 903-909.

Sankaram, M. B., and T. E. Thompson

1991 Cholesterol-Induced Fluid-Phase Immiscibility in Membranes. Proceedings of the National Academy of Sciences of the United States of America 88(19): 8686-8690.

Teixeira, Miguel C., Luís R. Raposo, Nuno P. Mira, Artur B. Lourenço, and Isabel Sá-Correia 2009 Genome-Wide Identification of Saccharomyces Cerevisiae Genes Required for Maximal Tolerance to Ethanol. Applied and Environmental Microbiology 75(18): 5761-5772.

Vanegas, Juan M., Maria F. Contreras, Roland Faller, and Marjorie L. Longo 2012 Role of Unsaturated Lipid and Ergosterol in Ethanol Tolerance of Model Yeast Biomembranes. Biophysical Journal 102(3): 507-516.

Verduyn, C., E. Postma, W. A. Scheffers, and J. P. van Dijken 1990 Physiology of Saccharomyces Cerevisiae in Anaerobic Glucose-Limited Chemostat Cultures. Journal of General Microbiology 136(3): 395-403.

Vriesekoop, Frank, Cornelia Haass, and Neville B. Pamment 2009 The Role of Acetaldehyde and Glycerol in the Adaptation to Ethanol Stress of Saccharomyces Cerevisiae and Other Yeasts. FEMS Yeast Research 9(3): 365-371.

Zheng, Z.

2001 The Initial Step of the Glycerolipid Pathway. IDENTIFICATION OF GLYCEROL 3PHOSPHATE/DIHYDROXYACETONE PHOSPHATE DUAL SUBSTRATE ACYLTRANSFERASES IN SACCHAROMYCES CEREVISIAE. Journal of Biological Chemistry 276(45): 41710-41716. 
Figures captions:

612 Fig.1: Impact of the initial phytosterol concentration on the fermentation kinetics (A) and

613 total population (B). The phytosterol range is between $0-8 \mathrm{mg} / \mathrm{L}$ with $0 \mathrm{mg} / \mathrm{L}$ (dark), 1

$614 \mathrm{mg} / \mathrm{L}$ (orange), $2 \mathrm{mg} / \mathrm{L}$ (violet), $3 \mathrm{mg} / \mathrm{L}$ (green), $5 \mathrm{mg} / \mathrm{L}$ (red) and $8 \mathrm{mg} / \mathrm{L}$ (blue).

615

616 Fig.2: Evolution of cell viability during the fermentation process for different initial

617 phytosterol concentrations and for the oxygen supply on a fermentation without

618 phytosterols. The phytosterol range is between 0 and $3 \mathrm{mg} / \mathrm{L}$ with $0 \mathrm{mg} / \mathrm{L}$ (dark), $0.5 \mathrm{mg} / \mathrm{L}$

619 (orange), $0.75 \mathrm{mg} / \mathrm{L}$ (violet), $1 \mathrm{mg} / \mathrm{L}$ (green), $2 \mathrm{mg} / \mathrm{L}$ (red), $3 \mathrm{mg} / \mathrm{L}$ (blue), and $0 \mathrm{mg} / \mathrm{L}+10$

$620 \mathrm{mg} / \mathrm{L}$ of $\mathrm{O}_{2}$ (grey).

622 Fig.3: Population level during the stationary phase according to the quantity of nitrogen

623 consumed at $60 \%$ fermentation. The tags correspond to the initial phytosterol

624 concentration and the dotted line represents the linear regression $\left(R^{2}=0.9873\right)$.

625

626 Fig.5: Residual nitrogen, at 60\% fermentation progress, of the oxygenated conditions

627 (blue) and without added oxygen (red), for different initial phytosterol concentrations.

629 Fig.4: Effect of adding $10 \mathrm{mg} / \mathrm{L}$ of oxygen at the Vmax during two hours underdifferent 630 phytosterol concentrations. The kinetics and population (blue squares) under oxygenated

631 conditions are shown in blue, whereas the kinetics and the population (red squares) for the 632 same condition without added oxygen are presented in red. The different phytosterol 
633 concentrations studied here are $0 \mathrm{mg} / \mathrm{L}(\mathrm{A}), 2 \mathrm{mg} / \mathrm{L}(\mathrm{B}), 3 \mathrm{mg} / \mathrm{L}(\mathrm{C}), 5 \mathrm{mg} / \mathrm{L}(\mathrm{D})$ and $8 \mathrm{mg} / \mathrm{L}$ $634(\mathrm{E})$.

635

636 Fig.6: Final concentrations of acetic acid (A), succinic acid (B) and glycerol (C) for different 637 initial phytosterol concentrations, with the conditions without oxygen in red and the 638 oxygenated conditions in blue.

639 Fig.7: Principal component analysis (PCA) of kinetics parameters (duration, maximum 640 growth rate (Vmax), Total cells number, viability and residual nitrogen) and primary 641 metabolites (acetic acid, glycerol and succinic acid). On the individual factor maps, 642 oxygenated modalities are represented in red and non-oxygenated modalities in blue. 